\title{
O trabalho no turismo como temática nos periódicos científicos associados aos programas Stricto Sensu em Turismo no Brasil
}

\section{The work in tourism as theme in the scientific journals associated to Stricto Sensu programs in Tourism in Brazil}

\author{
Denise de Souza (SOUZA, D. de)*
}

RESUMO - Este artigo resulta de pesquisa com caráter descritivo e bibliográfico que analisou as produções sobre a temática trabalho e turismo, publicados nos periódicos científicos associados aos programas Stricto Sensu em Turismo do Brasil. As edições analisadas compreenderam às disponibilizadas online até fevereiro de 2015, totalizando 1243 artigos verificados entre as revistas Turismo Visão e Ação, Revista Hospitalidade, Revista Rosa dos Ventos, Revista Turismo e Sociedade, Revista Turismo em Análise, Turismo Contemporâneo e Revista Cenário. A partir dos critérios metodológicos estabelecidos, foi possível selecionar aqueles que retrataram o trabalhador do turismo como protagonista do estudo elaborado. A partir dos resultados constatou-se um baixo número de produções que contemplaram os interesses e situação dos trabalhadores do Turismo, com maior número de estudos direcionados aos interesses das organizações e da gestão, que objetivaram a lucratividade e táticas de adequação do trabalhador às empresas.

Palavras-Chave: Turismo; Trabalho; Produções Científicas.

ABSTRACT - This descriptive and bibliographic research analyzed the productions on the theme work and tourism in scientific journals, published by Stricto Sensu programs in Tourism in Brazil. The editions analyzed considered the online journals available until February 2015, totalizing 1243 articles checked in the following journals: Turismo Visão e Ação, Revista Hospitalidade, Revista Rosa dos Ventos, Revista Turismo e Sociedade, Turismo em Análise, Turismo Contemporâneo and Revista Cenário. With the chosen methodology, it was possible to select those ones that portrayed tourism worker as protagonist of the study. The results found a low number of productions with the interests and situation of tourism workers, the majority part of the studies were addressed to the interests of organizations and management, with the goal of profitability and tactics to suit the worker to the companies.

Key words: Tourism; Work; Scientific Productions.

\footnotetext{
* Formação: Graduação em Turismo pelo Centro Universitário La Salle e Mestrado em Turismo pela Universidade de Caxias do Sul (UCS). Endereço físico para correspondência: Programa de PósGraduação em Turismo e Hospitalidade, Campus Universitário de Caxias do Sul - Bloco 46 - sala 416. CEP 95070-560 - Caxias do Sul - Rio Grande do Sul (Brasil). E-mail: des1301@ gmail.com
} 


\section{INTRODUÇÃO}

Dentre os envolvidos para que a atividade turística ocorra, estão além do turista e dos atrativos, também as empresas que prestam serviços e os trabalhadores que são a linha de frente do funcionamento da atividade turística. O trabalhador é, portanto, essencial no desenvolvimento do Turismo, mas verificou-se que acaba por participar nos estudos e pesquisas da área somente como coadjuvante dos assuntos, negligenciado como objeto de estudo nos periódicos científicos. Faz-se necessário, por isso, evidenciar em estudos, os interesses e a situação atual dos trabalhadores para que após, se possa pensar em suas contribuições ao setor a partir do conhecimento de sua situação enquanto sujeito que sofre e que tem dificuldades, dando voz ao seu papel fundamental para o desenvolvimento da atividade turística, enquanto trabalhador do Turismo.

Em contraponto, observou-se nas revistas científicas, o crescente número de pesquisas abordando as empresas e os atrativos, mas que não direcionavam ou aprofundavam os fatores humanos. Por conta disso, esta pesquisa objetivou demonstrar a contemplação do trabalhador no turismo em estudos, com um recorte em que se optou por abordar as publicações científicas reconhecidas no setor, interligadas aos Programas de Pós-Graduação em Turismo, do Brasil no ano de 2014 até fevereiro de 2015.

Obter informações atualizadas sobre os assuntos de pesquisa é um dos fatores que constroem pesquisas qualificadas, e as publicações nas revistas contribuem para disseminação do conhecimento sobre o assunto pesquisado. No Brasil, a Coordenação de Aperfeiçoamento de Pessoal de Nível Superior (CAPES), reúne através do Portal de Periódicos, uma biblioteca virtual, onde as instituições de ensino disponibilizam sua produção científica e atualmente o acervo conta com aproximadamente 35 mil periódicos (CAPES, 2014). Silva; Deboçã; Silva; Veiga (2012), destacam que a produção científica é responsável pela difusão de conhecimento entre estudiosos e sociedade e que a partir disso, diversos autores brasileiros têm buscado conhecer das mais diversas formas, dentre as mais diferentes áreas do conhecimento, a realidade dessa produção.

Cabe ao pesquisador refletir sobre a situação das produções científicas direcionadas ao turismo, já que estas são fontes primárias no fornecimento de informações aos estudantes e pesquisadores do meio, para a construção de seus novos 
estudos. No presente artigo, através de uma abordagem descritiva, se apresenta o resultado de uma pesquisa que consistiu em um levantamento nos periódicos, em busca de pesquisas que se referissem ao trabalhador, evidenciando de quais maneiras ele estava inserido nos objetivos e problemas dos estudos analisados.

Dentre os aspectos metodológicos disponíveis para pesquisas que realizaram análises nas produções publicadas, optou-se por realizar análise descritiva em relação aos objetivos da pesquisa, e bibliográfica em relação aos procedimentos, considerando que não foram encontrados estudos prévios sobre as publicações nas revistas dos Programas de Pós-Graduação em Turismo e Hospitalidade, referentes ao trabalhador do turismo, com os mesmos objetivos propostos. Portanto, este estudo visa facilitar a busca dos que, futuramente, desejarem aprofundar pesquisas com o tema Trabalho no Turismo, e que buscarem informações nas revistas científicas dos programas de Mestrado e Doutorado em Turismo e Hospitalidade no Brasil.

O artigo está estruturado em um referencial que demonstra as diferenças entre as denominações dadas ao trabalhador, explicitando os motivos da escolha do termo e sua significância no contexto da atividade turística. Seguindo para o item de metodologia onde estão descritas as ferramentas para seleção dos artigos e o item de discussões onde estão expostas as contribuições dos artigos selecionados.

\section{TRABALHO E TURISMO}

A escolha da denominação varia de acordo com quem a diz, como sinônimo de trabalho, são utilizadas expressões como emprego, ocupação, ofício, tarefa, função. Entretanto, o significado das expressões trabalho e trabalhador, justifica o porquê da escolha das mesmas quando se envolve a atividade turística. De acordo com o dicionário eletrônico Michaelis ${ }^{1}$ (2015, n.p), trabalhador é aquele "Dado ao trabalho; que gosta de trabalho; ativo; laborioso" e trabalho é o "Ato ou efeito de trabalhar. Exercício material ou intelectual para fazer ou conseguir alguma coisa. Esforço, labutação, lida, luta" (DICIONÁRIO ELETRÔNICO MICHAELIS, 2015, n. p). Sua definição já demonstra sua relação com o Turismo, já que é preciso de exercício

\footnotetext{
${ }^{1}$ Dicionário Eletrônico, não paginado.
} 
intelectual para trabalhar com o turismo, além das demais capacidades profissionais. É preciso gostar do seu trabalho para que ocorra o "bem receber o outro", ponto inicial para a hospitalidade. Além disso, é preciso ser ativo para lidar com a variedade de situações com as quais o trabalhador se depara em seu dia a dia de atividade.

De acordo com Trigo (2003), as pessoas do setor turístico trabalham onde outras se divertem, mas isso não significa que trabalhar no setor de lazer e diversões venha a ser divertido e prazeroso. "O senso comum pensa que trabalhar nessas áreas é "divertido" ou "gostoso" bastando ter uma "boa aparência" e vontade de se relacionar com outras pessoas" (TRIGO, 2003, p. 17). Esse pensamento de senso comum ignora o fato de que o outro, o trabalhador, está ali cumprindo suas atividades profissionais, sujeito a estar indisposto, triste, cansado, como todos os demais trabalhadores sentem-se frequentemente em seu ambiente de trabalho, abrindo mão de seus finais de semana, férias e feriados, exposto às consequências dos fatores psíquicos.

Christophe Dejours, criador da teoria da Psicodinâmica do Trabalho, coloca que o trabalho torna-se perigoso para o aparelho psíquico quando ele se opõe à sua livre atividade. O bem-estar, em matéria de carga psíquica, não advém só da ausência de funcionamento, mas, pelo contrário, de um livre funcionamento, articulado dialeticamente com o conteúdo da tarefa, expresso, por sua vez, na própria tarefa e revigorado por ela. Em termos econômicos, o prazer do trabalhador resulta da descarga de energia psíquica que a tarefa autoriza, o que corresponde a uma diminuição da carga psíquica do trabalho. A partir disso, os fatos tornam-se relativamente mais simples para serem interpretados: se um trabalho permite a diminuição da carga psíquica, ele é equilibrante. Se ele se opõe a essa diminuição, ele é fatigante (DEJOURS; ABDOUCHELI; JAYET, 1994, p. 25).

O não equilíbrio para o trabalhador afeta sua relação com o trabalho e com os demais trabalhadores, causa sofrimento, não havendo "capacitação coletiva" capaz de solucionar as relações de trabalho na instituição. Com isso, fica evidente a necessidade de compreender o trabalhador para que o turismo possa acontecer enquanto atividade qualificada. Antunes (2011) aprofunda o complexo mundo do trabalho no cenário atual brasileiro, que vai além da percepção sobre o cumprimento de algumas horas de atividade com o restante do tempo livre: 
Uma vida cheia de sentido em todas as esferas do ser social, dada a multilateralidade humana, somente poderá efetivar-se através da demolição das barreiras existentes entre tempo de trabalho e tempo de não trabalho, de modo que, a partir de uma atividade vital cheia de sentido, autodeterminada, para além da divisão hierárquica hoje vigente, que subordina o trabalho ao capital e, portanto, sob bases inteiramente novas, possa se desenvolver uma nova sociabilidade. Uma sociabilidade tecida por indivíduos (homens e mulheres) sociais e livremente associados, em que ética, arte, filosofia, tempo verdadeiramente livre e ócio, em conformidade com as aspirações mais autênticas, suscitadas no interior da vida cotidiana, possibilitem as condições para a efetivação da identidade entre indivíduo e gênero humano, na multilateralidade de suas dimensões, em formas inteiramente novas de sociabilidade, em que liberdade e necessidade se realizem mutuamente (ANTUNES, 2011, p. 113).

O autor evidencia com sua afirmação, a importância de pensar o trabalho como atividade realizada por sujeitos, ou indivíduos como o autor define, e consequentemente não considera-los como algo a ser dividido para rendimento maior como exige o capital. A partir do rompimento das barreiras descritas, há possibilidade do sujeito encontrar o equilíbrio psíquico citado anteriormente.

A luta pelos direitos do trabalhador em qualquer setor transpassa pela observação de sua situação de trabalho, de seu dia a dia e sua organização perante as tarefas que lhes são atribuídas, é preciso considerar e participar o trabalhador no turismo brasileiro. Heloani; Lancman (2004, p. 77), reforçam as diferentes dimensões do trabalho, quando afirmam que "O trabalho é mais do que o ato de trabalhar ou de vender sua força de trabalho em busca de remuneração. Há também uma remuneração social pelo trabalho, ou seja, o trabalho enquanto fator de pertinência a grupos e a certos direitos sociais" (HELOANI; LANCMAN, 2004, p. 77). Demonstrando assim que não se resume ao fato de compensação financeira e tornando-se atividade de influência na inserção do sujeito na sociedade. "O trabalho possui, ainda, uma função psíquica, enquanto um dos grandes alicerces da constituição do sujeito e da sua rede de significados (HELOANI; LANCMAN, 2004, p. 77)". O trabalho que se constitui como fator de inclusão social que interfere na vida do sujeito "é fonte de riqueza, fonte de prazer e também de realizações humanas. Ao realizar o trabalho, o homem abandona a dependência para com a natureza e entra na experiência do especificamente humano" 
(TOMAZZINI; MACÊDO, 2010, p. 210). No atual sistema capitalista, o trabalho deixou de ser o lugar das possibilidades e das expectativas para tornar-se o local do sofrimento, se consolidando como fonte de desprazer onde não há espaço para a criatividade do sujeito (OLIVEIRA, 2006).

Dejours; Abdoucheli; Jayet (1994, p. 129) afirmam que "para que a curiosidade fundamental do sujeito seja solicitada e ativada pelo encontro com a situação de trabalho, é necessário que a tarefa tenha um sentido para o sujeito, tendo em vista sua história singular". Para Dejours (2004, p. 28), "o trabalho sempre coloca à prova a subjetividade, da qual esta última sai acrescentada, enaltecida, ou ao contrário, diminuída, mortificada". O que expõe a importância da consideração da situação do trabalhador na sustentabilidade da atividade turística, o que torna os interesses dos trabalhadores, ponto alto a ser explorado na gestão das organizações e na tão abordada busca pela lucratividade.

Não é o simples ato de ir, cumprir tarefas e retornar ao seu lar, como se fosse possível um desligamento total de seu dia de trabalho, com isso não limitando o trabalho apenas como uma atividade; "ele é, também, uma forma de relação social, o que significa que ele se desdobra em um mundo humano caracterizado por relações de desigualdade, de poder e de dominação" (DEJOURS, 2004, p. 31). Demonstrando assim a relevância do trabalho na vida dos sujeitos e a possibilidade de maior compreensão da atividade turística a partir do olhar do trabalhador.

Nos estudos sobre a relação Trabalho e Turismo, destacam-se Bazotti (2014) que abordou o turismo de aventura e o trabalhador condutor de rafting, analisando as regras que orientam suas tarefas, e o risco que o condutor precisa assumir para dar conta da atividade, analisando a partir da Psicodinâmica do Trabalho de Christophe Dejours, demonstrando aspectos do prazer no trabalho, o risco, o medo, a valentia além das contradições frente às regras de segurança e a espetacularização da atividade, além do sofrimento no trabalho.

Bridi (2010) retrata o trabalho do Turismólogo, sua formação acadêmica e atuação profissional, direcionando esta atuação para as agências de turismo. Contrapondo competências e determinações presentes nas legislações sobre a formação do Turismólogo, o autor conclui em sua pesquisa que "mostra-se possível e pertinente, no contexto da contemporaneidade, uma inversão de foco no processo formativo, 
substituindo-se 'mercado turístico' por 'fenômeno turístico" (BRIDI, 2010, p. 8), pois dessa forma estaria sendo considerada a dimensão humana e os reflexos da dimensão humana do trabalho no Turismo "e, no caso específico (das agências de turismo), nas dimensões gerencial e operacional das agências, cujas relações se dariam com o Sujeito turista, cliente dessas organizações" (BRIDI, 2010, p. 8).

Para repensar a situação do trabalhador do Turismo, aquele que trabalha para o lazer do outro, Maya (2008) expõe os aspectos do trabalho e do tempo livre, trazendo o capitalismo para essa dimensão do tempo do trabalhador: que vende sua força de trabalho, e que fica com o tempo livre, o tempo que lhe sobra, para comprar o seu lazer. Mas o lazer comprado se dá de acordo com as possibilidades de cada um, o que difere a burguesia do trabalhador assalariado. "O tempo livre, dentro do quadro das relações capitalistas, geralmente é encarado como uma compensação ao sofrimento imposto pelo trabalho e/ou como uma simples forma de reprodução da força de trabalho" (MAYA, 2008, p. 43). Ou seja, "o tempo, na sociedade capitalista, transformou-se em uma mercadoria que pode ser adquirida num mercado de bens simbólicos e consumida de acordo com as possibilidades de cada um" (MAYA, 2008, p. 43). Como então compreender àquele sujeito que vende seu "tempo de trabalho" para que o outro compre seu "tempo de lazer", uma relação que quando analisada, pode contribuir para melhor desenvolvimento da atividade turística, por isso a importância de ouvir o que o trabalhador tem a dizer sobre si e sobre si com seu trabalho.

\section{METODOLOGIA}

A pesquisa consistiu na análise e seleção dos artigos de todas as edições dos periódicos anunciados, vinculados ou associados aos programas de Pós-Graduação em Turismo constantes no Portal da Capes. (CAPES, 2015). O procedimento realizado foi de pesquisa bibliográfica, onde o pesquisador faz um levantamento do conhecimento disponível na área, identificando as produções teóricas e avaliando a contribuição das mesmas para auxiliar na compreensão do objeto de investigação. Sendo importante para ampliar o nível de conhecimento capacitando o pesquisador a compreender melhor e dominar o conhecimento disponível (KOCHE, 2009). A pesquisa bibliográfica também 
contribui com explicações a partir dos referenciais teóricos, pois "procura explicar um problema a partir de referências teóricas, publicadas em artigos, livros, dissertações e teses. Pode ser realizada independente ou como parte da pesquisa descritiva ou experimental" (CERVO; BERVIAN; SILVA, 2007, p. 60). Em ambos os casos descritos pelos autores o objetivo é conhecer e analisar as contribuições culturais ou científicas sobre determinado assunto, tema ou problema, até um momento atual. (CERVO; BERVIAN; SILVA, 2007).

A pesquisa é considerada descritiva, pois não está somente demonstrando as publicações resultantes de análise bibliográfica, está também se propondo a descrever um fenômeno atual. A pesquisa descritiva é a que estuda as relações entre duas ou mais variáveis de um dado fenômeno sem manipulá-la (KOCHE, 2009). A população pode ser considerada como a comunidade acadêmica do turismo, que pesquisa e publica nos periódicos científicos dos programas. As variáveis seriam as publicações sobre trabalho que contemplassem o trabalhador e as publicações que tratassem sobre o trabalho, não contemplando o fator humano. A pesquisa bibliográfica de acordo com Marconi; Lakatos (2008, p. 43) é aquela em que a "finalidade é colocar o pesquisador em contato direto com tudo aquilo que foi escrito sobre determinado assunto, com o objetivo de permitir ao cientista o reforço paralelo na análise de suas pesquisas ou manipulação de suas informações (MARCONI; LAKATOS, 2008, p. 43), também contribui com explicações a partir dos referenciais teóricos.

Assim o estudo seguiu as seguintes etapas: a) identificação dos Programas de Pós-Graduação em Turismo no Portal da Capes (CAPES, 2015); b) identificação dos periódicos vinculados a esses programas, através de consulta ao website de cada programa; c) verificação da ocorrência das expressões "trabalho" e "trabalhador" através de busca que contemplassem todas as seções dos artigos, nas edições disponíveis; d) leitura do resumo e palavras-chave dos selecionados onde foram encontradas as expressões, para verificar se o artigo tratava-se de pesquisa sobre a relação trabalho e turismo; e) seleção daqueles que abordassem a relação trabalho e turismo para leitura de todas as seções; f) leitura dos selecionados, com análise do problema de investigação, objetivo, principais contribuições, autoria, forma de participação dos trabalhadores na pesquisa e principais referenciais utilizados; h) análise e interpretação dos resultados encontrados. $\mathrm{Na}$ busca dos artigos, foram considerados 
apenas os periódicos vinculados ou associados aos programas Sricto Sensu reconhecidos pela Capes:

TABELA 1 - CURSOS RECOMENDADOS E RECONHECIDOS NA ÁREA DO TURISMO PELA COORDENAÇÃO DE APERFEIÇOAMENTO DE PESSOAL DE NÍVEL SUPERIOR

\begin{tabular}{lccc}
\hline PROGRAMA & IES & UF & MODALIDADE \\
\hline Gestão de Negócios Turísticos & UEC & CE & Mestrado Profissional \\
Hospitalidade & UAM & SP & Mestrado Acadêmico \\
Turismo & UNB & DF & Mestrado Profissional \\
Turismo & UFPR & PR & Mestrado Acadêmico \\
Turismo & UFRN & RN & Mestrado Acadêmico \\
Turismo & USP & SP & Mestrado Acadêmico \\
Turismo & UCS & RS & Mestrado Acadêmico \\
Turismo e Hotelaria & UNIVALI & SC & Mestrado Acadêmico e \\
\hline
\end{tabular}

FONTE: CAPES (2014).

Consultados os endereços eletrônicos de cada Programa, pôde-se constatar que no Programa de Gestão de Negócios Turísticos (UECE) não havia até o momento de pesquisa, periódicos disponíveis para consulta. Após o levantamento inicial, a busca foi realizada nos artigos de todas as edições de cada periódico, considerando somente os disponibilizados por meio eletrônico, via website individual.

TABELA 2 - REVISTAS VINCULADAS OU ASSOCIADAS AOS PROGRAMAS DE PÓSGRADUAÇÃO

\begin{tabular}{llll}
\hline \multicolumn{1}{c}{ REVISTA } & PROGRAMA DE PÓS-GRADUAÇÃO A QUE ESTA \\
& VINCULADA & & Q \\
\hline Revista Hospitalidade & Mestrado em Hospitalidade - UAM & & \\
Revista Cenário & Mestrado em Turismo - UNB & & \\
Revista Turismo e Sociedade & Mestrado em Turismo - UFPR & & \\
Revista Turismo Contemporâneo & Mestrado em Turismo e Doutorado - UFRN & & \\
Revista Turismo em Análise & Mestrado em Turismo - USP & \\
Revista Rosa dos Ventos & Mestrado em Turismo- UCS & \\
Revista Turismo Visão e ação & Mestrado em Turismo e Doutorado - UNIVALI & \\
\hline
\end{tabular}

FONTE: Elaboração própria (2014).

A Revista Hospitalidade iniciou sua circulação em 2004, sendo de responsabilidade do Programa de Mestrado em Hospitalidade da Universidade Anhembi Morumbi e publicada semestralmente. Tem como objetivo reunir reflexões e pesquisas 
científicas referentes à temática da hospitalidade em todas as suas vertentes. Aceita comunicações na forma de artigos, ensaios, informações sobre pesquisas em andamento, apresentando ainda todos os resumos das dissertações defendidas no Mestrado e resenhas de livros (REVISTA HOSPITALIDADE, 2014).

A Revista Cenário é associada ao Programa de Pós-Graduação em Turismo da Universidade de Brasília, publica semestralmente trabalhos inéditos, com foco na interdisciplinaridade, sobre pesquisas na área de Turismo e áreas afins (REVISTA CENÁRIO, 2014).

A Revista Turismo e Sociedade é um periódico científico eletrônico editado pelo Departamento de Turismo da Universidade Federal do Paraná e associado ao mesmo, de publicação semestral. Tem como missão e objetivos, publicar estudos, pesquisas e relatos de experiência de docentes, pesquisadores e profissionais na área de Turismo (REVISTA TURISMO E SOCIEDADE, 2014).

A Revista Turismo Contemporâneo é editada pelo Programa de PósGraduação em Turismo da Universidade Federal do Rio Grande do Norte (PPGTUR/UFRN), a publicação é semestral e tem como missão “contribuir para a construção do conhecimento científico na área de Turismo, por meio da divulgação de estudos e pesquisas de alto nível de qualidade" (REVISTA TURISMO CONTEMPORÂNEO, 2014).

As duas revistas com maior número de publicações foram a Turismo em Análise e a Turismo Visão e Ação. A Revista Turismo em Análise é editada pelo Departamento de Relações Públicas, Propaganda e Turismo da Escola de Comunicações e Artes da Universidade de São Paulo a missão é "a difusão de pesquisas, experiências científicas e estudos desenvolvidos por docentes, pesquisadores e profissionais na área de Turismo, Lazer e Hospitalidade” (REVISTA TURISMO EM ANÁLISE, 2014).

A Revista Turismo Visão e Ação (2014) está vinculada ao Programa de PósGraduação em Turismo e Hotelaria da Universidade do Vale do Itajaí (UNIVALI). É um periódico científico de publicação quadrimestral. O público-alvo é composto principalmente de pesquisadores, professores e alunos da graduação e da pós-graduação em Turismo e áreas afins; como também por consultores, empresários e profissionais de empresas públicas e privadas que atuam nessas áreas. São submetidos ao periódico, 
artigos inéditos, sejam teóricos ou teórico-empíricos, nacionais ou internacionais que abordem temas relevantes (REVISTA TURISMO VISÃO E AÇÃO, 2014).

A Revista Rosa dos Ventos (2013) é um periódico acadêmico dedicado à reflexão e à discussão sobre o Turismo e temas transversais. Iniciou em 2009, estando interligado ao Programa de Mestrado em Turismo da Universidade de Caxias do Sul. Os temas abordados pela revista abrangem aspectos relacionados ao Turismo, com foco na hospitalidade, na gestão, na cultura, no meio ambiente, na educação e na epistemologia (REVISTA ROSA DOS VENTOS, 2014).

As buscas pelos termos foram realizadas em cada uma das revistas, em seu sistema próprio de buscas, totalizando 1.293 artigos onde buscou-se as expressões descritas anteriormente. Estes referem-se à totalidade dos artigos disponibilizados online até o período de análise: Fevereiro de 2015. Nos artigos onde houve a ocorrência das expressões, foi feita a leitura do resumo e palavras-chave. Após esta leitura, foram descartados aqueles que não contemplavam o objetivo deste estudo: o trabalhador no turismo. Dentre os artigos descartados, estavam aqueles em que a expressão foi utilizada somente como complementação de uma frase e também artigos onde o trabalhador foi entrevistado para falar sobre sua empresa. Também foram descartados aqueles que abordavam o mercado de trabalho, os treinamentos para força de trabalho, os que utilizaram a expressão "trabalho" como sinônimo de "pesquisa", artigos sobre a gestão de pessoas que abordavam formas de gestores relacionarem-se com os trabalhadores para aprimorar desempenhos nas empresas, pois não faziam parte dos objetivos deste artigo. Os estudos que restaram após os filtros de seleção, foram os descritos no Quadro 1.

QUADRO 1 - INFORMAÇÕES SOBRE OS ARTIGOS SELECIONADOS PARA LEITURA DE TODAS AS SEÇÕES

\begin{tabular}{|c|c|}
\hline TÍTULO DO ARTIGO SELECIONADO PARA LEITURA & REVISTA \\
\hline $\begin{array}{l}\text { Militante Político Republicano, Charles Ribeyrolles e a hospitalidade no } \\
\text { Brasil império. }\end{array}$ & $\begin{array}{l}\text { Revista Hospitalidade } \\
\text { (v. } 6, \text { n. 1) }\end{array}$ \\
\hline $\begin{array}{l}\text { A relação entre turistas estrangeiros e residentes: o caso de Ponta Negra - } \\
\text { Natal/RN. }\end{array}$ & $\begin{array}{l}\text { Revista Hospitalidade } \\
\text { (v. 7, n. 2) }\end{array}$ \\
\hline $\begin{array}{l}\text { Comprometimento Organizacional: um estudo de caso no setor de governança } \\
\text { hoteleira. }\end{array}$ & $\begin{array}{l}\text { Revista Hospitalidade } \\
\text { (v. 7, n. 2) }\end{array}$ \\
\hline Por um novo horizonte profissional do Turismólogo. & $\begin{array}{l}\text { Revista Rosa dos } \\
\text { Ventos (v. 3, n. 3) }\end{array}$ \\
\hline
\end{tabular}


Continuação.

\begin{tabular}{|l|l|}
\hline $\begin{array}{l}\text { Incorporación al Turismo Rural y Transformación del Habitus em la Mujer } \\
\text { Campesina de San Pedro Atlapulco, México. }\end{array}$ & $\begin{array}{l}\text { Revista Rosa dos } \\
\text { Ventos (v. 4, n. 2) }\end{array}$ \\
\hline $\begin{array}{l}\text { Transformações do bairro da Vila Olímpia em São Paulo, Brasil (2000 a a } \\
\text { 2013) e as percepções da hospitalidade no espaço urbano. }\end{array}$ & $\begin{array}{l}\text { Revista Turismo e } \\
\text { Sociedade (v. 7, n. 4) }\end{array}$ \\
\hline $\begin{array}{l}\text { Predição dos valores pessoais sobre percepção de justiça de funcionários que } \\
\text { atuam com turismo em empresas do Distrito Federal. }\end{array}$ & $\begin{array}{l}\text { Revista Turismo Visão } \\
\text { e Ação (v. 6, n. 3) }\end{array}$ \\
\hline $\begin{array}{l}\text { Ter funcionários satisfeitos é ter clientes satisfeitos: realidade ou indícios? } \\
\text { Um estudo em agências de viagens. }\end{array}$ & $\begin{array}{l}\text { Revista Turismo Visão } \\
\text { e Ação (v.10, n.1) }\end{array}$ \\
\hline Educação Profissional em Turismo. Cria-se Mercado pela Formação? & $\begin{array}{l}\text { Revista Turismo em } \\
\text { Análise (v. 18, n. 2) }\end{array}$ \\
\hline
\end{tabular}

FONTE: Elaboração própria (2014).

\section{DISCUSSÕES}

É importante iniciar destacando que não cabe aqui uma afirmação de que o trabalhador não aparece nos estudos em turismo já que a presença do trabalhador pode ser vista nos artigos que abordam a Gestão: na competitividade, ou na referência a maior necessidade de qualificação profissional, na realização de treinamentos, ou sendo consultado sobre algum aspecto da organização em que atua. Na educação: nas abordagens ao Turismólogo e aos cursos para formação profissional, direcionados prioritariamente a necessidade de maior qualificação profissional. Nas investigações sobre as organizações, como agências de viagens e turismo, hotéis, atrativos turísticos, dentre outras. Nas pesquisas sobre políticas públicas para geração de empregos através do Turismo. No entanto, nessas abordagens o trabalhador aparece em contextos diferentes dos propostos por este estudo.

As denominações aos trabalhadores nos artigos descartados também foram encontradas em forma de outras expressões: retratados pelas suas funções e cargos, como diretores, coordenadores, agricultores, empresários, empreendedores, funcionários e guias de turismo. Mas como previamente quando foi justificado o motivo da escolha pela expressão "trabalhador", foram considerados somente os denominados nesse contexto. Os artigos que foram considerados como alinhados aos objetivos da pesquisa após a leitura integral de suas seções, de abordar o trabalhador no turismo totalizaram 9 artigos como se demonstrou no quadro 1 . Um baixo número quando comparado à totalidade dos artigos pesquisados. Além disso, algumas revistas como a Cenário e a 
Turismo Contemporâneo não apresentaram artigos sobre o assunto proposto no objetivo desta pesquisa.

Outra observação que cabe a ser discutida é o número acentuado de artigos que abordavam o fator social e humano como objeto de interesse das organizações em busca de maior competitividade:

Uma das motivações para uma empresa aderir à responsabilidade social se deve à competitividade que redireciona o poder para as mãos do novo consumidor, [...] em um ambiente competitivo, as empresas investem em ações sociais, a fim de promover sua imagem (ARAÚJO; CASTRO, 2013, p. 265).

Em outras publicações, o trabalhador aparece embutido nas expressões "manutenção de pessoas", "força de trabalho", "capital humano", além das pesquisas onde estão táticas e técnicas para que os trabalhadores se tornem "mais simpáticos" para atender melhor.

Dentre os artigos onde o trabalhador estava contemplado, destaca-se o estudo de Santos Filho (2009), em uma pesquisa sobre a hospitalidade e os aspectos históricos sobre o Brasil Império e a escravidão, trazendo ideais de Charles Rybeirolles, militante político republicano e citando os trabalhadores em diversos momentos, falando sobre o direito ao trabalho livre: "Brasileiros, não sois nem botocudos, nem purís, nem portugueses. Sois da filiação humana, tendes avós como nós todos. Homens e povos, não há mais sobre a terra nem velhos, nem moços, nem grandes, nem pequenos. Só há trabalhadores" (RIBEYROLLES, 1980², apud SANTOS FILHO, 2009, p. 34). Em alguns dos estudos, a consideração com a qualidade de vida do trabalhador e sua relação com o turismo, é evidenciada: "qualidade de vida do trabalhador poderá refletir diretamente na qualidade do atendimento ao visitante e na maior orientação para o mercado. (TORNIERI; BAPTISTA; TOALDO; ROGLIO, 2012, p. 416).

Em pesquisa realizada por Aires; Pequeno; Fortes (2010), dados sobre a relação comercial que os trabalhadores estabelecem com os turistas, reforçam o contato direto do trabalhador informal que inclusive relata manter conversas informais com os turistas, fazendo o uso até mesmo de mímicas e gestos quando não é possível comunicação em

2 RIBEYROLLES, C. Brasil pitoresco: história, descrição, viagem, colonização, instituições. Belo Horizonte: Itatiaia; São Paulo: Universidade de São Paulo, 1980. 
mesmo idioma. Os trabalhadores em questão, da Praia de Ponta Negra em Natal, afirmaram que seu maior contato com os turistas ocorria durante o trabalho.

O artigo de Vidal; Simonetti (2010) considera em suas seções os comportamentos do trabalhador, descrevendo seus interesses. Entretanto, o objetivo do estudo foi o de encontrar maneiras de aprimorar o comprometimento organizacional por parte dos trabalhadores, em favorecimento das organizações por acreditar que o comprometimento através do que denominam de "contrato psicológico" é um conceito para aprimorar a relação harmoniosa em prol da empresa. O que demonstra que mesmo quando as características e aspectos do trabalhador estão presentes, elas objetivam uma moldura para o benefício das organizações. Entretanto, como o objetivo deste estudo era demonstrar a contemplação do trabalhador, pode-se considerar que o trabalhador está contemplado neste estudo, não em seus interesses, mas na descrição de seus comportamentos e relações de trabalho.

Gonzalez; Cabianca (2014) realizaram estudo sobre percepções de moradores e trabalhadores do bairro da Vila Olímpia na cidade de São Paulo sobre as dimensões da hospitalidade exercida em espaços urbanos, nas entrevistas realizadas com os trabalhadores. Nos relatos, estão opiniões sobre as modificações na cidade com o passar dos anos e as formas de interferência dos fatores em seu dia a dia de trabalho. Contemplando a situação do trabalhador e relacionando com as dimensões da hospitalidade, demonstrando assim a importância dos trabalhadores na relação Trabalho $\mathrm{x}$ Turismo.

Yazigi (2011), em sua pesquisa direcionada para o trabalho do Turismólogo e a necessidade de mudanças na formação acadêmica para o Turismo refere-se ao trabalho através de críticas às diretrizes do Ministério da Educação em relação ao Turismo então vigentes. $\mathrm{O}$ autor mencionou acreditar que:

[...] não pode existir uma articulação capaz de dispor na mesma plataforma, por exemplo, um barman, que é um dos elementos do serviço turístico, com um museólogo que também se devota à mesma missão, apesar de ambos se preocuparem em satisfazer uma clientela que ultrapasse turistas (YAZIGI, 2011, p. 425).

As críticas também são direcionadas a atual organização do trabalho, acreditando ser "ser cada vez mais difícil se um diploma não se posicionar num campo operacional bem definido" (YAZIGI, 2011, p. 425). Os interesses dos trabalhadores 
estão sendo expostos enquanto defesa de uma modificação do sistema de ensino para atuação profissional.

Relatando a formação profissional para o Turismo, Tomazzoni (2007) considera o trabalhador como significante para o mercado de trabalho. Seu estudo da empregabilidade em Turismo, como atividade econômica, enfoca o papel do indivíduo na sociedade do trabalho, em relação à sociedade de consumo e do lazer como produto. Destaca a apropriação da força de trabalho pelas empresas, pois, na economia capitalista "o trabalhador passou a vender também o seu tempo livre e a destinar o resultado da sua luta diária pela sobrevivência - o salário - para a compra ou o consumo de lazer" (TOMAZZONI, 2007, p. 199). O artigo evidencia um importante aspecto que é a venda do tempo livre pelo trabalhador e retrata uma realidade que diferencia os que desfrutam do lazer "como forma de aproveitamento do tempo livre" (p. 199), daqueles que "sequer têm acesso ao mercado de trabalho e à renda para poderem consumir o lazer como produto, que desenvolve o Turismo como atividade que "industrializa" o ócio" (TOMAZZONI, 2007, p. 199).

O enfoque dado ao trabalhador neste artigo é um diferencial, pois não há referência ao trabalhador da mesma maneira nas demais análises sobre as abordagens de Trabalho e Turismo. A complexidade de abordar o trabalho na área do Turismo é descrita pelo autor quando afirma que "pode ser mais complexa do que em outros setores, tanto pelas suscetibilidades aos fatores sociais e demográficos, aos quais esta atividade econômica está submetida, quanto em razão da diversidade de segmentos que a compõem" (TOMAZZONI, 2007, p. 201). No trecho a seguir, considera-se que o autor consegue de forma clara expor a situação do trabalhador no Turismo no Brasil, com abordagens ao capitalismo e ao uso da força de trabalho:

É na contextualização capitalista que se situa a análise da situação do trabalhador no setor de turismo, a exemplo de outros setores da economia. Os atributos do trabalhador como qualificação e competência, poderiam ser definidos como mercadorias das quais o mercado capitalista se apropria para viabilizar seus objetivos de produção e de lucro. O trabalhador vende sua força de trabalho e seu tempo sob um processo de negociação que pode ser competitivo ou institucionalizado, dependendo do grau de envolvimento, interferência e controle das diversas organizações da sociedade, como governos e sindicatos. Uma das formas de regulação dessa negociação de compra e venda é o salário, que remunera o trabalhador e cujo valor pode variar de acordo com a realidade de cada setor de atividade econômica (TOMAZZONI, 2007, p. 200). 
Nas pesquisas, também se encontra a relação do trabalhador com outros fatores de sua vida, como no artigo de Ramirez; Villareal; Contreras (2012) que expõe a realidade da mulher incorporada ao trabalho rural e as transformações de seus hábitos, trazendo informações sobre os aspectos sociais nas mudanças e os reflexos na unidade familiar. Souto e Oliveira (2008) utilizam informações coletadas com funcionários de agências viagens para expor a satisfação do trabalhador com sua atividade afirmando que a satisfação garante um bom relacionamento com o cliente no setor de serviços (SOUTO; OLIVEIRA, 2008). São consideradas na pesquisa, algumas questões como satisfação com o trabalho, relacionamento com as chefias, qualidade de treinamento, benefícios, concluindo que o uso de pesquisas internas podem indicar práticas e políticas para modificações nas empresas para o bem-estar do trabalhador (SOUTO; OLIVEIRA, 2008).

O artigo de Souza; Pérez-Nebra; Tamayo (2004), sobre as percepções de justiça nas organizações do Turismo, contribui para o entendimento da situação do trabalhador:

\begin{abstract}
No contexto organizacional, a constatação de que atitudes e comportamentos relevantes para o trabalho dependem dos julgamentos e avaliações acerca da in/justiça organizacional vem desafiando a área de pesquisa sobre percepção de justiça. Tem-se que a falta de justiça nas organizações no tratamento dos seus empregados está associada a comportamentos negativos que perturbam a vida da organização, tais como roubos, rotatividade, absenteísmo, envolvimento em conflitos com os colegas de trabalho, atividades de retaliação e reações de estresse (SOUZA; PÉREZ-NEBRA; TAMAYO, 2004, p. 244).
\end{abstract}

Nas discussões de resultados, o trabalhador é contemplado em relatos de seus desejos, sofrimentos e enfrentamentos perante situações de trabalho. Os autores descrevem como contribuição da pesquisa, o fato de ser a primeira pesquisa acadêmica realizada com a temática da percepção de justiça com trabalhadores do Turismo, e corroboram com esta pesquisa quando afirmam ter encontrado poucas pesquisas sobre o mundo do trabalho no Turismo (SOUZA; PÉREZ-NEBRA; TAMAYO, 2004).

Inúmeros podem ser os fatores que resultam em poucos estudos sobre o trabalhador do turismo, em razão da variedade de atividades que podem ser realizadas para que se considere um "trabalhador do turismo". Um jardineiro pode ser considerado, por criar cenários que serão apreciados pelos visitantes. Um faxineiro contribui para manter os atrativos turísticos possíveis de visitação. Uma recepcionista de hotel 
contribui para a hospitalidade com os hóspedes que atende. Dentre essa variedade de atividades, o destaque seria a importância de se estar atento aos direitos dos trabalhadores de modo geral, para que assim, se possa planejar o desenvolvimento sustentável da atividade turística.

\section{CONSIDERAÇÕES FINAIS}

Os artigos foram lidos com muito cuidado em todas as suas seções, para que se pudesse afirmar com clareza quais tratavam sobre o trabalhador, a situação do trabalho no turismo, qual cenário atual, entretanto os resultados não contemplaram o que era esperado. Os focos dos estudos onde surgiram a expressão trabalho ou trabalhador(es), não trouxeram informações sobre os mesmos, alguns estudos até trouxeram aspectos do dia a dia de trabalho, mas não direcionando para o trabalhador e sim para o turista ou para a empresa, organização, instituição e demais denominações.

Não se objetivou fazer uma crítica às abordagens de trabalho no turismo dos periódicos, o que se buscou foi um alerta sobre a posição do trabalhador, que acaba ficando como coadjuvante em busca da qualidade do serviço para maior obtenção de lucros, para o sucesso das empresas, para a gestão de negócios.

Expõem-se aqui a necessidade observada, de reflexão sobre o assunto e de mais estudos que investiguem e que tenham como objetivo, compreender o trabalhador e os aspectos que concorrem de seu trabalho, a relação com o visitante sob o seu olhar, a relação com a instituição sob o seu olhar. Isso, para que se possam compreender melhor as formas de trabalho no turismo, carências, vantagens, desvantagens, necessidades.

Entretanto, salienta-se um fator positivo que foi a participação desses trabalhadores nas pesquisas, através de questionários ou entrevistas, mesmo que com objetivos sempre de conversar sobre outros assuntos, sobre a organização em que trabalham, mas da mesma forma ganhando voz nos estudos científicos do turismo. 


\section{REFERENCIAS}

AIRES, J. D. M; PEQUENO, E. A; FORTES, L. A relação entre turistas estrangeiros e residentes: o caso de Ponta Negra - Natal/RN. Revista Hospitalidade, São Paulo, v. 7, n. 2, p. 38-51, jul.-dez. 2010.

ANTUNES, R. Adeus ao Trabalho? Metamorfoses e a Centralidade do Mundo do Trabalho. 15. ed. São Paulo: Cortez, 2011.

ARAÚJO, M. P. F; CASTRO, C. L. C. Políticas de gestão de pessoas destinadas aos profissionais com deficiência: um estudo em uma organização hoteleira da cidade do Rio de Janeiro, Revista Turismo Visão e Ação, v. 15, n. 2, p. 262-278, 2013.

BAZOTTI, L. Atividade turística de Rafting e os sentidos da segurança para seus condutores: Rios Paranhana e Antas em Três Coroas e Nova Roma do Sul/RS. 2014. 148f. Dissertação (Mestrado em Turismo e Hospitalidade) - Universidade de Caxias do Sul, Programa de Pós Graduação em Turismo e Hospitalidade, Caxias do Sul, 2014.

BRIDI, G. Formação e atuação do turismólogo no cenário das agências de turismo: contrapondo competências. 2010. 150 f. Dissertação (Mestrado em Turismo) Universidade de Caxias do Sul, Programa de Pós Graduação em Turismo e Hospitalidade, Caxias do Sul, 2010. Disponível em: $<$ https://repositorio.ucs.br/jspui/bitstream/11338/729/1/Dissertacao\%20Guilherme\%20 Bridi.pdf >. Acesso em: 01/05/2015.

CAPES. COORDENAÇÃO DE APERFEIÇOAMENTO DE PESSOAL DE NÍVEL SUPERIOR. Disponível em: <www.capes.gov.br>. Acesso em: 01/12/2015.

COORDENAÇÃO DE APERFEIÇOAMENTO DE PESSOAL DE NÍVEL SUPERIOR. Disponível em:<www.capes.gov.br>. Acesso em: 20/03/2015.

CERVO, A. L; BERVIAN, P. A; SILVA, R. Metodologia Científica. 6. ed. São Paulo: Pearson Prentice Hall, 2007.

DEJOURS, C.; ABDOUCHELI, E.; JAYET, C. Psicodinâmica do Trabalho: contribuições da escola Dejouriana à Análise da Relação Prazer, Sofrimento e Trabalho. São Paulo: Atlas, 1994.

DEJOURS, C. Subjetividade, Trabalho e Ação. Revista Produção, Santa Catarina, v. 14, n. 3, p. 027-034, 2004.

GONZALEZ, L. L; CABIANCA, M. A. A. Transformações do bairro da Vila Olímpia em São Paulo, Brasil (2000 a 2013) e as percepções da hospitalidade no espaço urbano. Turismo \& Sociedade, Curitiba, v. 7, n. 4, p. 775-791, outubro de 2014.

HELOANI, R; LANCMAN, S. Psicodinâmica do trabalho: o método clínico de intervenção e investigação. Revista Produção, v. 14, n. 3, p. 077-086, 2004. 
KÖCHE, J. C. Fundamentos de metodologia científica: teoria da ciência e iniciação à pesquisa. 26. ed. Petrópolis, RJ: Vozes, 2009.

MARCONI, M; LAKATOS, E. Fundamentos de Metodologia Científica. São Paulo: Atlas, 2008.

MICHAELIS, Dicionário Eletrônico de Língua Portuguesa. São Paulo: Melhoramentos, 2015. Disponível em: < http://michaelis.uol.com.br>. Acesso em: 20 mar. 2015.

OLIVEIRA, C. B. de. Sobre lazer, tempo e trabalho na sociedade de consumo. Revista Digital, Buenos Aires, año 11, n. 97, jun. 2006. Disponível em: <http:// www.efdeportes.com>. Acesso em: 08/04/2013.

RAMIREZ, C. P; VILLAREAL, L. Z.; CONTRERAS, S. M. Incorporación al Turismo Rural y Transformación del Habitus em la Mujer Campesina de San Pedro Atlapulco, México. Revista Rosa dos Ventos, v. 4, n. 2, p. 158-177, abr.-jun., 2012.

REVISTA TURISMO: VISÃO E AÇÃO. Universidade do Vale do Itajaí. Itajaí, 2013. Disponível em: <http://siaiweb06.univali.br/seer/index.php/rtva>. Acesso em: 19/09/2013.

REVISTA HOSPITALIDADE. Universidade Anhembi Morumbi. São Paulo, 2013. Disponível em: <http://revhosp.org/ojs/index.php/hospitalidade>. Acesso em: 08/10/2013.

REVISTA ROSA DOS VENTOS. Universidade de Caxias do Sul. Caxias do Sul, 2013. Disponível em: <http://www.ucs.br/etc/revistas/index.php/rosadosventos>. Acesso em: 19/09/2013.

REVISTA TURISMO CONTEMPORANEO. Programa de Pós Graduação em Turismo da Universidade Federal do Rio Grande do Norte. Natal, 2013. Disponível em: <http://www.incubadora.ufrn.br/index.php/turismocontemporaneo/index >. Acesso em: 08/10/2013.

REVISTA TURISMO E SOCIEDADE. Departamento de Turismo da Universidade Federal do Paraná. Curitiba, 2013. Disponível em: <http://ojs.c3sl.ufpr.br/ojs2/index.php/turismo/index>. Acesso em: 01/10/2013.

REVISTA CENÁRIO. Programa de Pós-Graduação em Turismo da Universidade de Brasília. 2014. Disponível em:

<http://periodicos.unb.br/index.php/revistacenario/índex>. Acesso em: 10/10/2014.

REVISTA TURISMO EM ANÁLISE. Universidade de São Paulo, 2014. Disponível em: <http://www.turismoemanalise.org.br/turismoemanalise>. Acesso em: 10/10/2014.

SANTOS FILHO, J. Militante Político Republicano, Charles Ribeyrolles e a hospitalidade no Brasil Império. Revista Hospitalidade, v. 6, n. 1, p. 16-33, 2009. 
SILVA, P. R.; DA-SILVA, P. R.; DEBOÇÃ, L. P.; SILVA, A. J. H; VEIGA, R. T. Uma análise da produção científica nos periódicos de Turismo sobre o tema comportamento do consumidor em turismo. Revista Turismo Visão e Ação, Itajaí, v. 14, n. 1, p. 47-66, jan./abr., 2012.

SOUTO, C. M. R.; OLIVEIRA, L. M. B. Ter funcionários satisfeitos é ter clientes satisfeitos: realidade ou indícios? Um estudo em agências de viagens. Revista Turismo Visão e Ação, v. 10, n.1, p. 75-93, jan./abr. 2008.

SOUZA; L. D; PÉREZ-NEBRA, A. R; TAMAYO, A. Predição dos valores pessoais sobre percepção de justiça de funcionários que atuam com turismo em empresas do Distrito Federal. Revista Turismo Visão e Ação, v. 6, n. 3, p. 243-252, set./dez. 2004.

TOMAZZINI, T.; MACÊDO, K. B. As vivências dos trabalhadores de um Shopping Center em relação ao seu trabalho: uma abordagem Psicodinâmica. RGO- Revista Gestão Organizacional, Chapecó, v. 3, n. 2, p. 210-224, 2010.

TOMAZZONI, E. Educação Profissional em Turismo. Cria-se Mercado pela Formação? Revista Turismo em Análise, São Paulo, v. 18, n. 2, p. 197-219, 2007.

TORNIERI, S.; BAPTISTA, P. P.; TOALDO, A. M. M.; ROGLIO, K. D. D. Parque Nacional do Iguaçu: Contribuição das práticas de Gestão Estratégica de pessoas para a redução de barreiras internas à implementação da orientação para o mercado. Revista Turismo Visão e Ação, v. 14, n. 3, p. 401-418, 2012.

TRIGO, L. G. G. A sociedade pós-industrial e o profissional em turismo. 7. ed. Campinas, SP: Papirus, 2003.

VIDAL, M. P.; SIMONETTI, V. M. M. Comprometimento Organizacional: um estudo de caso no setor de governança hoteleira. Revista Hospitalidade, v. 7, n. 2, p. 111-137, 2010 .

YAZIGI, E. Por um novo horizonte profissional do Turismólogo. Revista Rosa dos Ventos, v. 3, n. 3, 2011.

Recebido em: 15-04-2016.

Aprovado em: 15-05-2016. 